\title{
A Microscopia por Varrimento de Sensor (SPM)
}

\author{
J. BORGES DE ALMEIDA*
}

\section{INTRODUÇÃO}

Foi em 1982 que Binning e Rohrer inventaram o microscópio de efeito túnel que, por permitir uma resolução atómica, abriu à comunidade científica novos horizontes no que respeita à observação directa da estrutura dos materiais.

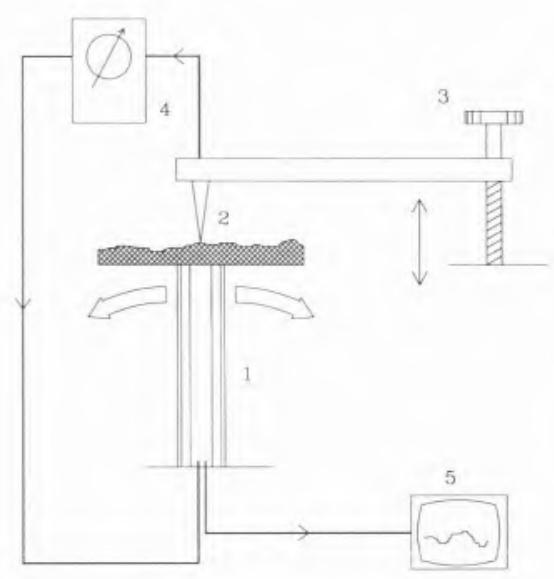

Fig. 1 - Esquema de um microscópio de varrimento de sensor

O mesmo princípio básico usado para a formação de imagens no microscópio de efeito túnel, ou seja o varrimento de toda a amostra por um sensor numa sucessão de linhas de varrimento paralelas, foi desde então aplicado a uma grande variedade de sensores, dando origem à família dos microscópios de varrimento de sensor (Sacanning Probe Microscopes, SPM) dos quais os que têm apresentado resultados mais espectaculares são, sem dúvida, os microscópios de força atómica (Atomic Force Microscopes, AFM) e os de efeito túnel (Scanning Tunneling Microscopes, STM).

A figura 1 esquematiza o funcionamento de um microscópio SPM. Este é constituído por um sistema de varrimento da amostra (1), geralmente por meio de um elemento piezoeléctrico, de um sensor (2) com um sistema grosseiro de aproximação da amostra (3) e de um medidor do sinal do sensor (4) incorporado numa malha de realimentação para o controlo fino da aproximação da amostra ao sensor. Um computador de controlo (5) actua sobre o sistema de varrimento, recolhe os dados do medidor de sinal e converte-os em imagem.

Na altura em que este artigo foi inicialmente escrito, os melhores microscópios faziam o varrimento da amostra mantendo fixo o sensor; hoje em dia existem modelos de grande qualidade em que se opta por mover o sensor mantendo fixa a amostra. Os princípios gerais de funcionamento são idênticos e muitas das considerações feitas podem ser transpostas ou adaptadas para os microscópios de amostra fixa.

\section{OS DIFERENTES TIPOS DE SENSORES}

\subsection{Microscópio de força atómica}

Neste caso o sensor é constituído por uma ponta aguçada, colocada na ponta de uma viga (cantilever) com $100 \mu \mathrm{m}$ a $200 \mu \mathrm{m}$ de comprimento; a altura da ponta é de alguns micra e tem um diâmetro nominal na ponta de menos de $100 \AA$.

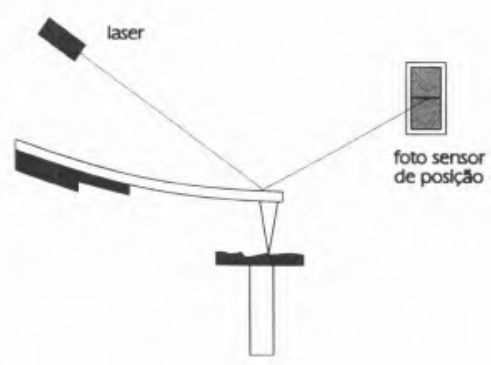

Fig. 2 - Detecção do encurvamento da viga

O sinal que é recolhido pela ponta resulta do encurvamento da viga, o qual é medido pela deflexão de um feixe laser, figura 2, ou pela variação do valor de uma piezo-resistência incorporada na própria viga. A deflexão da viga resulta das forças interatómicas, essencialmente forças de Van der Waals, entre a ponta e a amostra, figura 3, as quais se podem apresentar repulsivas ou atractivas, consoante a distância entre os átomos.

\subsubsection{Modo de contacto}

Quando a ponta é levada a um contacto físico com a amostra as forças predominantes são repulsivas e a viga curva-se originando um sinal no detector (ver figura 2).

$\mathrm{O}$ varrimento da amostra origina uma variação na curvatura da viga, enquanto a ponta não perder o contacto com a amostra. Temos assim um primeiro modo de representar a superfície da amostra, que consiste em representar o valor da curvatura para cada ponto da superfície.

O método anterior não produz uma verdadeira representação topográfica mas se permitirmos que a malha de realimentação mova a amostra, por forma a manter a curvatura da viga constante, o movimento vertical pode ser usado para representação da topografia.

As forças de repulsão em jogo podem ir desde zero até um valor típico de $10^{-7}$ a $10^{-6} \mathrm{~N}$; inesperadamente é geralmente possível operar em modo de contacto com forças atractivas que podem chegar a atingir $10^{-8} \mathrm{~N}$, devido à camada de água que existe geralmente sobre a superfície e que segura a ponta à amostra, por capilaridade, antes de a deixar soltar-se.

\subsubsection{Modo de não-contacto}

Em modo de não-contacto as forças são atractivas de baixo valor, cerca de $10^{-12} \mathrm{~N}$; este baixo valor é importante para não deformar amostras delicadas mas a força atractiva torna o sistema instável, porque a aproximação à amostra corresponde a um aumento do valor da força.

Neste modo trabalha-se com vigas mais rígidas e, para dar estabilidade ao sistema, a agulha e a viga vibram próximo da frequência natural de oscilação. A distância entre a ponta e a amostra afecta a frequência de ressonância, pelo que a variação dessa distância vai alterar a am- 
plitude da oscilação e também a sua frequência; se o arranjo for tal que a uma aproximação corresponda uma diminuição de amplitude, o sistema tornou-se estável. O sinal recolhido pode ser retirado da amplitude ou da frequência da oscilação; naturalmente pode operar-se em amplitude, ou frequência, variáveis, mantendo constante a altura da amostra, ou em amplitude, ou frequência, fixas, sendo a malha de realimentação responsável pelo movimento vertical da amostra e permitindo uma representação topográfica.

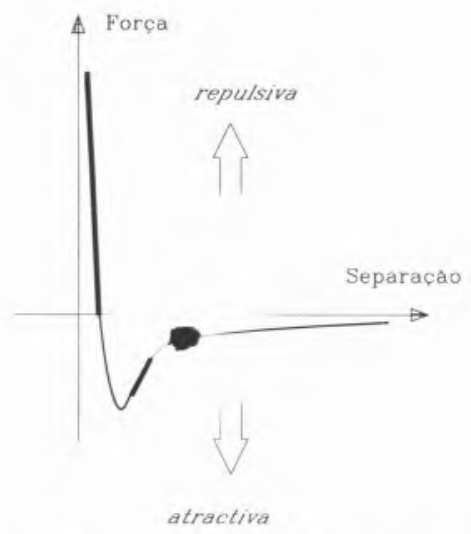

Fig. 3 - Força de Van der Waals versus separação ponta-amostra. A linha carregada indica as duas zonas de operaçâo.

Em modo de contacto a representação corresponde à superfície da amostra porque a água que se encontra sobre esta é perfurada pela ponta; em modo de não-contacto a imagem que se forma é, na realidade, a da superfície da água depositada ou de quaisquer outras impurezas que não sejam arrastadas pela ponta.

\subsubsection{Modo de toque}

(Tapping Mode)

Trata-se de uma variação do modo de não-contacto em que se permite que a agulha chegue a tocar na superfície, perfurando assim a camada de água. As forças em jogo têm que ser suficientes para que a agulha volte a soltar-se da superfície, mas evitam-se as forças laterais existentes no modo con- tacto e que resultam do atrito da ponta sobre a superfície.

\subsection{Microscópio de força lateral}

Um aperfeiçoamento do microscópio de força atómica permite detectar não só o encurvamento da viga como a sua torção, a qual está relacionada com as forças laterais que são aplicadas sobre a ponta. Estas podem resultar do relevo da superfície mas podem também ser devidas a zonas com diferentes coeficientes de fricção. O Microscópio de Força Lateral (Lateral Force Microscope, LFM) permite recolher alguma informação adicional sobre a amostra; a interpretação dos resultados obtidos pode levantar algumas dificuldades.

\subsection{Microscópio de força magnética}

O Microscópio de Força Magnética (Magnetic Force Microscope, MFM) é também uma variação do AFM; agora a ponta é coberta com uma camada ferromagnética e previamente magnetizada, permitindo uma representação das forças magnéticas entre ponta e a amostra. A imagem obtida pode conter informação relativa a forças magnéticas e forças atómicas sobrepostas e poderão ser necessárias várias imagens obtidas a diferentes distâncias para discriminar entre os dois tipos de informação.

\subsection{Microscópio de efeito túnel}

O microscópio de efeito túnel (STM) foi o pioneiro dos SPM's; o sensor é constituído por uma ponta de um material condutor de electricidade, colocado a uma distância da ordem dos $10 \AA$ de uma amostra, também ela condutora. A distâncias desta ordem uma corrente eléctrica passa entre a ponta e a amostra por efeito túnel, corrente que é exponencialmente dependente da distância. Naturalmente que o STM pode operar tanto em modo de corrente constante como em modo topográfi- co, de forma análoga aos modos de força constante e topográfico do AFM; no entanto o STM mede uma propriedade da amostra diferente da que é medida pelo AFM e duas imagens topográficas da mesma amostra obtidas por processos diferentes podem não ser iguais.

\subsection{Outros tipos de sensores}

Merecem ainda referência outras técnicas que têm sido relatadas mas que se encontram ainda em desenvolvimento ou cuja aplicação é limitada:

- Microscópio Óptico de Campo Próximo (Scanning Near-Field Optical Microscope, SNOM), usa como sensor um "funil de luz" o qual permite colocar sobre a amostra um ponto luminoso com uma ou duas centenas de angstroms de diâmetro e obter uma imagem óptica de alta resolução;

- Microscópio de Força Electrostática (Electrostatic Force Microscope, EFM), usa uma tensão de polarização entre a ponta e a superfície para que se manifestem forças electrostáticas. Uma variação deste princípio permite construir um Microscópio de Varrimento de Capacidade (Scanning Capacitance Microscope, SCM).

\subsection{Influência do ambiente}

O ambiente mais habitual para utilização de SPM's é a própria atmosfera; no entanto algumas amostras exigem ambientes especiais dos quais se referem o ultra alto vácuo ou as temperaturas controladas, que exigem aparelhos especialmente construídos para o efeito; e os ambientes líquidos ou as células electroquímicas que são simples adaptações no instrumento básico.

\section{O SISTEMA DE VARRIMENTO}

Quase todos os microscópios de varrimento de sensor dispõem de um sistema piezoeléctrico como sistema de alta resolução para posicionar a amostra sob o sensor (ou o sensor 


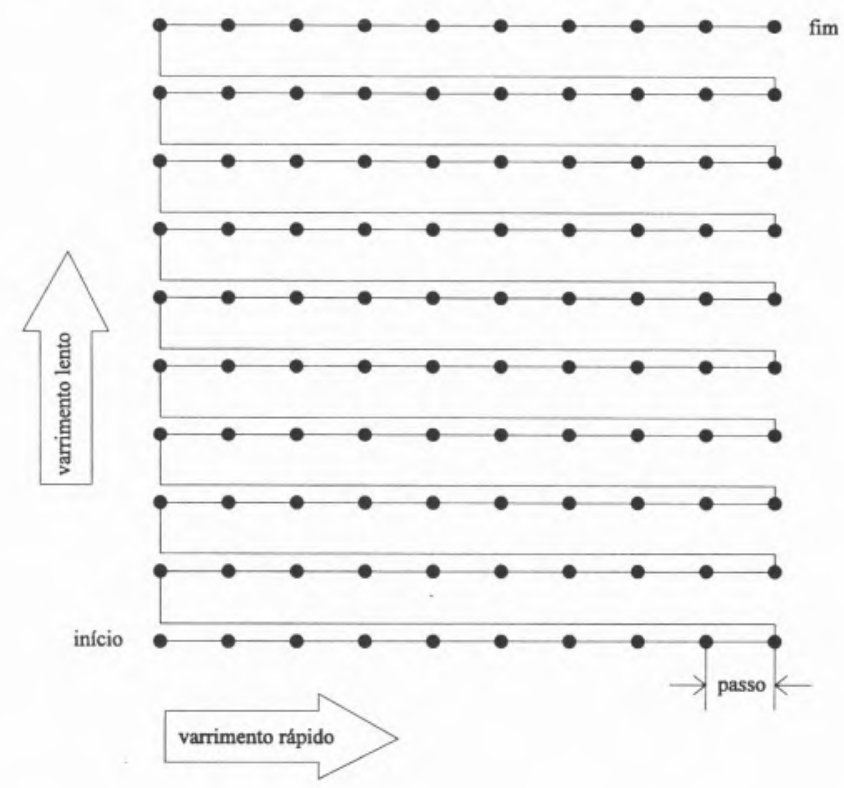

Fig. 4 - Varrimento durante a aquisição de dados

sobre a amostra). Os circuitos electrónicos comandam o posicionamento formando um padrão de linhas paralelas, semelhante ao da exploração de um cinescópio de televisão. $\mathrm{O}$ sistema explora a primeira linha em pequenos passos e depois volta ao início; passa então à segunda linha, à terceira, etc. até à última. A aquisição de dados é feita apenas numa das direcções em cada linha, sendo o retorno feito sem aquisição; a direcção das linhas é a direcção de varrimento rápido e a direç̧ão perpendicular é a direcção de varrimento lento; habitualmente são adquiridos 256 ou 512 pontos por linha e é explorado um número igual de linhas, resultando num total de $256 \times 256$ ou $512 \times 512$ pontos.

O passo é a distância entre dois pontos consecutivos e naturalmente resulta da divisão da amplitude do varrimento pelo número de pontos por linha; a amplitude pode ir de algumas dezenas de angstroms até às centenas de micra.

\subsection{Aspectos construtivos}

Como se disse é um material piezoeléctrico que é responsável tubo sgmentado não só pelo varrimento nas direcções X e Y mas também pelo movimento vertical da amostra, direcção Z. A forma habitual de construção é a ilustrada na figura 5 e consiste num poste com a forma de um cilindro oco. Nas paredes externa e interna do cilindro existem eléctrodos, sendo o interno inteiro e o exterior dividido em quatro por separações verticais.

Alguns construtores optam por um sistema de varrimento baseado

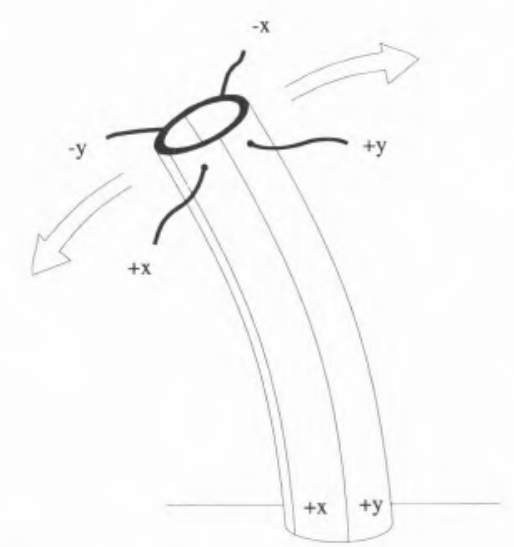

Fig. 5 - Sistema de varrimento piezoeléctrico de em três actuadores lineares, segundo os três eixos, em vez do sistema poste aqui descrito.

Como é sabido, um material piezoeléctrico varia as suas dimensões por efeito de campos eléctricos aplicados. O arranjo dos eléctrodos é tal que permite encurvamentos do poste em todos os planos e também extensão ou contracção vertical.

A simplicidade e reduzidas dimensões deste sistema são acompanhadas, infelizmente, de inúmeras não-linearidades, que em vários casos não podem ser corrigidas por uma tabela de conversão; este é o caso, por exemplo da histerese. A única correç̧ão correcta para os problemas de não-linearidade consiste em dotar o sistema de sensores de posição de grande fiabilidade nos três eixos e aplicar aos eléctrodos as tensões que, em cada circunstância, se revelem necessárias para atingir a posição desejada. Sistemas de varrimento que se baseiam na linearidade do sistema ou que fazem uma linearização por meio de tabela de correcção não merecem confiança.

Há vários testes que se podem fazer para testar a linearidade, nomeadamente:

1 - Fazer a imagem de uma grelha bem conhecida e que obrigue a varrimento amplo.

2 - Fazer a imagem da mesma superfície trocando o sentido do varrimento rápido.

3 - Fazer um zoom rápido num canto de uma imagem.

4 - Fazer a imagem da superfície de uma lente de contacto e comparar o raio obtido com o raio conhecido da lente.

\section{A PONTA E A VIGA DE AFM}

As vigas e pontas de AFM são habitualmente fabricadas em silício. $\mathrm{O}$ desenho quer da viga quer da ponta tem em vista determinadas aplicações e o utilizador precisa de ter à sua disposição uma gama variada, a não ser que faça um uso repetitivo do seu microscópio. Além 
disso, as pontas gastam-se com facilidade e é importante que a substituição se possa fazer sem grandes atribulações. Para utilizações em ambientes diferentes da atmosfera deve haver a garantia de se poderem experimentar várias pontas sem necessidade de trazer o sistema para a atmosfera.

\subsection{Propriedades da viga}

As vigas para AFM têm habitualmente uma forma triangular para garantir uma elevada resistência lateral e uma razoável "moleza" vertical. A constante de mola da viga, que caracteriza o seu comportamento, pode variar numa gama de quatro ordens de grandeza mas deve manter-se abaixo dos valores característicos para os átomos num sólido, cerca de $10 \mathrm{Nm}^{-1}$. As frequências de ressonância podem ir dos poucos kilohertz até várias centenas de kilohertz. Em geral, para o modo de contacto, as vigas serão compridas e terão uma constante de mola baixa e para o modo de não-contacto serão mais rígidas e com elevadas frequências de ressonância.

\subsection{A forma da ponta e a resolução}

A resolução lateral é determinada, em primeiro lugar, pelo passo do varrimento; quando este se torna inferior a cerca de $50 \AA$ passa a ser determinante a ponta, já que o valor mínimo de raio disponível tem aquele valor. Estas considerações aplicam-se em geral a singularidades da superfície; no entanto para estruturas periódicas como a estrutura atómica de um cristal, poderá conseguir-se resolução atómica porque os vários átomos da extremidade da ponta sofrem todos uma perturbação com a mesma frequência espacial, reproduzindo-se assim correctamente as constantes geométricas de uma estrutura periódica até à escala atómica. Alguns resultados recentes, no entanto, mostram já verdadeira resolução atómica obtida em AFM.
A forma da ponta é importante quando se encontram elementos da superfície com declives superiores ao da ponta. Neste caso dá-se uma convolução entre a forma da ponta e o elemento da superfície, a qual se manifesta geralmente pela repetição de uma mesma forma geométrica, correspondente a uma secção recta da ponta, em vários pontos da imagem. Os efeitos de convolução com a ponta podem ser confirmados produzindo uma imagem da amostra rodada de um ângulo conhecido e verificando se as formas observadas sofrem ou não a mesma rotação.

Em STM, pelo contrário, a dependência exponencial da corrente em relação à distância permite conseguir que seja apenas um átomo da ponta a conduzir a corrente e que se obtenha uma verdadeira resolução atómica.

\section{ALGUNS EXEMPLOS DE UTILIZAÇÃO}

Os exemplos que se seguem foram gentilmente cedidos pela CRIOLAB e resultam de observações feitas nas instalações daquela empresa, usando um microscópio Park Scientific.

\section{Departamento de Física, Largo do Paço, 4709 Braga Codex \\ Texto e desenhos do autor inicialmente publicado por CRIOLAB Lda e agora adaptado. Inspirado em: "How to buy a Scanning Probe Microscope". R. S. Howland, Park Scientific Instruments, 1993}

* Universidade do Minho, Escola de Ciências

Nota do editor: um outro artigo sobre esta técnica, escrito em italiano, foi anteriormente publicado no Química: B. Samorì, Química - Boletim da Sociedade Portuguesa de Química, 55, (1994) 38 .

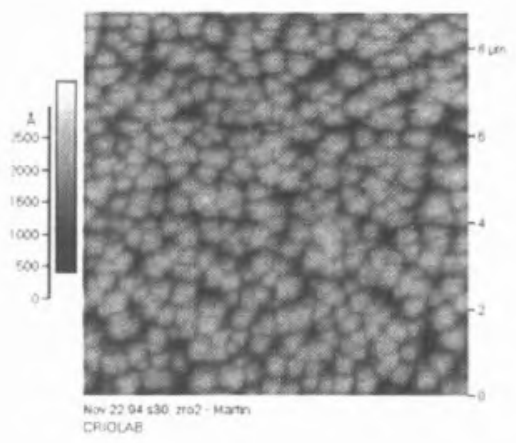

Fig. 6 - Filme de óxido de zircónio

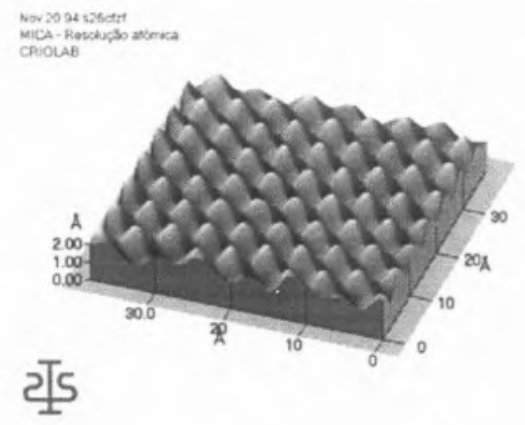

Fig. 7 - Demonstração da resolução atómica numa observação de átomos de mica

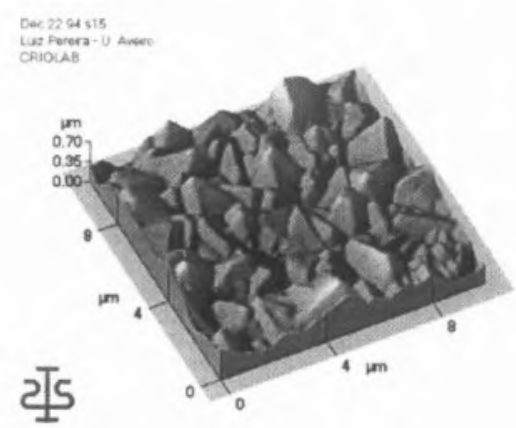

Fig. 8 - Filme de diamante 